\title{
Crítica del lenguaje en la poesía hispanoamericana. Estudio del período modernista*
}

\author{
A critique on language in Hispano-American Poetry. \\ A study on Modernism
}

\section{Felipe García Quintero}

Universidad del Cauca, Colombia

DOI: https://doi.org/10.32719/13900102.2019.45.8

Fecha de recepción: 16 enero 2019

Fecha de aceptación: 29 abril 2019

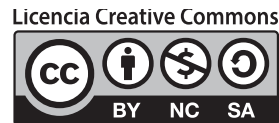

* Resultado parcial del proyecto de investigación "Poética y lenguaje. Crisis de la representación comunicativa. Fase I". ID 5141, Vicerrectoría de Investigaciones, Universidad del Cauca, Colombia. 


\section{RESUMEN}

La pregunta que procura atender este artículo se orienta a pensar cómo es asumida la conciencia crítica del lenguaje en el modernismo hispanoamericano, por tratarse de un problema literario y filosófico frente al lenguaje surgido de considerar que la confianza en la palabra fue uno de los principales postulados para superar la crisis finisecular del XIX, con lo cual se buscó la salvación espiritual a través de la trascendencia estética. La respuesta a este problema estético y filosófico se expresa en una reflexión dedicada al análisis del fenómeno en las poéticas del lenguaje de J. Martí, J. Asunción Silva, R. Darío y M. Ángel Silva. De igual modo, este ejercicio se provee de un recorrido por los principales hitos de la filosofía del lenguaje y establece con ello un panorama de los conceptos y las categorías como una apuesta clasificatoria del problema a nivel temático. Ha sido un propósito estudiar la crisis y la crítica del lenguaje en la poesía de Hispanoamérica como un aporte para la compresión de nuestra tradición literaria, asunto que encuentra en el período modernista uno de sus fundamentos de mayor creatividad expresiva y diálogo cultural, cuyo ascendiente determina en gran medida el estado presente de la poesía contemporánea. Palabras Clave: Hispanoamérica, poesía, crítica, crisis, lenguaje, poéticas, modernismo, modernidad.

\section{ABSTRACT}

The question that this article intends to answer aims towards thinking how the consciousness of critic in Hispano-American Modernism is assumed, since it is a literary and philosophic problem regarding the language arisen from the consideration that confidence in words was one of the main postulates that took part in overcoming the Nineteenth century crisis, with which spiritual salvation was sought, through aesthetical transcendence. The answer to this aesthetic and philosophic problem is expressed in a reflection dedicated to the analysis of said phenomenon in the poetics of language in J. Martí, J. Asunción Silva, R. Darío and M. Ángel Silva. In the same extent, this exercise thrives on a journey through the main landmarks of the Philosophy of Language and, with this, establishes a panorama of concepts and categories as a classifying bet of the problem at a thematic level. The objective has been to study Language crisis and critiques in Hispanic-American poetry as a contribution to the understanding of our literary tradition. Said issue finds in Modernism one of its most important foundations in what regards expressive creativity and cultural dialogue, which determines -to a great extent- the present state of contemporary poetry.

KEYwORDS: Hispanic America, poetry, critique, crisis, language, poetics, Modernism.

\section{PRESENTACIÓN}

DADO EL PREDOMINIO crítico del espíritu moderno que conjuga teoría y creación en un mismo ámbito, la poesía en Occidente es la más radical experiencia del lenguaje. Los límites entre las fronteras de los géneros se 
desdibujan, y por su efecto, los discursos artísticos, antes excluyentes del quehacer literario, hoy son una toma de conciencia del mundo. De este modo se avanza en el camino temerario de la negación creativa hacia el conocimiento del ser y la realidad existencial. En busca de las respuestas a los antiguos misterios, la poesía moderna ha explorado sin reserva regiones desconocidas, espacios nuevos, fenómenos humanos nunca antes nombrados. Y sobre la actualidad de las manifestaciones producidas bajo los cambios socioculturales de las revoluciones políticas y tecnológicas, aún en marcha, la lírica ha querido ser el testimonio que denuncia los desmanes y desvíos del lenguaje.

El principio y el final de esa indagación frenética por el sentido se hallan en la palabra y la escritura como dos realidades que se corresponden al mismo hecho creador. El lenguaje determina la búsqueda y condiciona el camino del conocimiento, pues aquello que puede ser dicho yace en lo escrito como símbolo. Acerca de este problema sensible y significativo, versan las siguientes consideraciones que toman como eje la poética modernista, cuyos casos a estudiar encontramos representativos.

\section{CRISIS Y CRÍTICA DEL LENGUAJE: CATEGORÍAS TEÓRICAS Y CLASIFICACIÓN TEMÁTICA}

Si la crisis y la crítica fundamentan la realidad del hecho poético contemporáneo, cabe preguntar ahora ¿en qué consiste este fenómeno de modernidad literaria? A partir de una descripción conceptual del problema, entramos a definir las categorías teóricas y la clasificación temática del mismo, visto como una propuesta de análisis de la estética modernista en Hispanoamérica, que se verá ejemplificada con algunos poemas tomados como objeto de una glosa crítica.

El primer presupuesto teórico lo establece el significado esencial de la toma de conciencia sobre el lenguaje, conducente a desarrollar una reflexión de la poesía misma. Esta reflexión es crítica, porque cuestiona el estatuto teórico del arte y con ello las bases propias del ser y la existencia humana se someten a revisión, generando la inevitable crisis de la identidad estética y de la autoría. Además, la reflexión no es solo teórica, sino también creativa, porque el ejercicio crítico se ejerce al seno de la propia 
poesía, bajo la modalidades del discurso metaliterario y de la autorreferencialidad.

Por lo anterior, el ejercicio crítico como reflexión artística halla en el poema autorreferencial -aquel que habla de sí mismo desde sí mismo para sentar los fundamentos del ser literario-, la revisión del estatuto ontológico de la representación estética. El metatexto hace de la escritura un juego de miradas: aquel ver mirándose a sí mismo. Las aristas temáticas de la conciencia crítica se proyectan generalmente en dos direcciones: una, la del proceso creador del poema (el acto escritural) y dos, el de la poética (la definición de la poesía o del pensamiento estético que reflexiona sobre su esencia nocional). Es importante destacar que la autorreferencialidad significa también la autonomía del objeto verbal. Al no haber referencialidad por fuera del texto, se renuncia a la mimesis y el poema se convierte, simultáneamente, en signo y cosa (Pérez Parejo 2002, 113-70).

$\mathrm{Al}$ realizarse desde dos ámbitos diferentes y complementarios -el metapoema y la crítica literaria y filosófica-, la crisis del lenguaje debe entenderse como resultado de un fenómeno global de secularización de la modernidad literaria. La capacidad crítica del poeta cuestiona la realidad hasta el punto de lograr la separación del orden analógico tradicional, lo cual conlleva a desalojar lo sagrado y a romper los vínculos antiguos del lenguaje aurático, aquel investido de poder de representación, en tanto unidad de sentido y sonido.

Recordemos que lo sacro era el lugar de la palabra y la cosa, la única entidad capaz de la representación completa, total del universo, y de la comunicación plena entre los hombres. La rotura, la separación y la escisión son las marcas que hacen de la poesía contemporánea el escenario de un drama humano, donde la fragmentación de la voz en mitades irreconciliadas ha reemplazado la unidad del mundo original, cuyas partes incompletas sustituyen el todo perdido. De tal suerte que el poema y su escritura son testimonios de una pugna, del conflicto por la expresión humana que busca recuperar o dar nuevo sentido al mundo.

La lengua poética es objeto de inquietudes, asedios, dudas y recelo. Estas manifestaciones crecientes de sospecha y amenaza de la capacidad significativa del lenguaje son originadas por el conflicto de la incomunicación lingüística de la poesía. Lo que a su vez deriva en una crisis de los valores de representación estética: la palabra es insuficiente para los propósitos inherentes del arte como es la búsqueda de lo bello, y resulta pobre 
para el diálogo humano, porque ha perdido su potencia de identificación para vincular la diferencia con la pluralidad simbólica de la semejanza. En el habla del poeta moderno se instala la mudez, el silencio; la impotencia expresiva lo lleva al desencanto, luego a la esterilidad y a vivir las carencias del lenguaje como camino de creación.

Todo horizonte en este camino resulta negativo. Al cabo de recorrerlo, el poeta dice no saber decir y escribe no poder escribir. Cambia entonces la figura tradicional del vidente y demiurgo, dueño del poder verbal, por la crítica de la autoría que lleva a cabo un proceso de autodesmitificación, donde el fracaso artístico y la ruina estética consecuente del poema como acto fallido se han traducido progresivamente en pérdida del estilo, crisis de identidad y muerte del autor.

En el marco crítico de la autoría como drama de la impotencia artística, las nuevas realidades temáticas del poema son la escenificación trágica y paródica del acto escritural, asistida por el recurso de la autorreferencialidad y el discurso metaliterario que explora la intimidad de la creación antes vedada al lector. Mediante modalidades enunciativas como la confesión biográfica de la experiencia creadora, por ejemplo, leemos las tribulaciones y sentimos las caídas del autor en su lucha por expresar el poema, de materializar su idea en formas verbales siempre esquivas, incompletas o defectuosas, lejanas del deseo de fijeza, plenitud y belleza que lo angustia, a las cuales se entrega sin éxito, o bien renuncia a sabiendas que en ese juego sin certezas solo el intento vano es su apuesta.

Del tal suerte, la escritura no siempre es algo logrado en la voz que ya tampoco garantiza fijar el pensamiento estético. Esto hace del poema una suerte de didáctica del error, donde salen a relucir los secretos procedimientos de la escritura metaliteraria. Lo fallido del intento es la expresión del fracaso. El resultado se mide en el grado de ironía que conlleva la expresión, pues escribir el poema del fracaso constituye el fracaso mismo del poema, celebrado como lección deificante, mas carente de sentido y valor trascendentes. Gracias al truco retórico de enmarañar con lucidez la expresión, el poeta logra la paradoja lingüística de una enunciación de lo vacuo. Se trata también del drama caracterizado por Heidegger (1987) del poeta poseído por el habla y no poseedor de ella.

La paradoja irónica de la enunciación poética muestra la desintegración del yo autoral en la fragmentación de los signos. Esta rotura de la sacralidad del poema moderno se aprecia, además, cuando la escritura se 
distancia de su creador. La conciencia crítica ha distinguido entre autor, texto y voz, y por ende, ha separado el yo textual del yo autorial. Advertimos que fracasar en el cometido de la expresión impide al poeta reconocerse en la escritura. En el juego vacuo de decir que no se puede decir, no hay poema ni existe autor. La pérdida del estilo y de la identidad del sujeto creador son dos características temáticas de la crítica del lenguaje que la poesía hispanoamericana desarrolla a partir del modernismo hasta nuestros días, en una línea de continuidad irregular, cuyas discontinuidades históricas son el resultado de la trama de corrientes y tradiciones diferenciadas, algo no siempre advertido por la capacidad proteica de la poesía para ser distinta y ocultarse bajo el influjo de una transformación creadora modelante de la conciencia crítica.

Tenemos entonces que el poema es la pugna entre autor, voz y texto, donde el monólogo es la forma verbal enunciativa de un sujeto escindido en pluralidades distanciadas de la unidad verbal de palabra y acto. La espiral de la autorreferencialidad se cierra en la negación crítica de la experiencia poética como crisis del significado del lenguaje.

Se advierte entonces como en la poesía contemporánea europea e hispanoamericana, la crítica del lenguaje se ejerce y desarrolla a modo de un tema recurrente de asuntos diversos, pero exclusivo de la doble mirada sobre el valor del signo escrito para representar la realidad y comunicar el pensamiento, esto en relación al papel del escritor que entra en un proceso de desmitificación. La esencia mágica de la palabra fundacional, ahora secularizada como legado divino, adenda de su potencia creadora, mas perdida en la voz estéril del poeta como el gran artífice derrotado, son los dos tópicos generales del tratamiento estético del lenguaje en tanto crisis y crítica del estatuto cultural moderno.

\section{CRÍTICA DEL LENGUAJE EN LA POESÍA HISPANOAMERICANA DEL SIGLO XX. EL MODERNISMO: RESTAURACIÓN Y RENOVACIÓN DEL LENGUAJE POÉTICO}

Para la historia de la poesía hispanoamericana el movimiento modernista es el más importante de los acontecimientos de apertura cultural y proyección estética del siglo XX. También lo es de toma de conciencia del 
lenguaje, pues se lo considera el período en que América Latina conquista la mayoría de edad literaria y define su identidad, al lograr una expresión propia, que toma distancia de la tradición colonial mimética, para nombrar las realidades de un conglomerado social, donde históricamente el mestizaje ha respondido a complejos procesos de formación cultural, y privilegiar ciertos imaginarios letrados. ${ }^{1}$ En suma, el modernismo poético se alza como la mayor conquista verbal. Por ello, resulta significativo que Rafael Gutiérrez Girardot (1983) concluya su estudio dedicado a este período de las letras hispanas del siguiente modo:

Con el modernismo, esta mentalidad se había abierto al mundo, había asimilado el pensamiento y la literatura europeos del siglo XIX, se había puesto, en ocasiones a su altura, y había perfilado su especificidad. Los países de lengua española ya no deberían considerarse zonas marginales de la literatura mundial.

La modernidad literaria que nace con los autores de la primera generación -Martí, Gutiérrez Nájera, del Casal, Silva y Darío-, lo sabemos, es sincrética; pues, el proceso de asimilación de valores estéticos y de síntesis de la tradición poética europea y cosmovisión americana explica el carácter ecléctico de la poesía modernista, de cuyas tendencias se incorporan, renovadas, la visión romántica del amor y la libertad; la sugerencia simbolista; la belleza enferma del decadentismo y la precisión parnasiana, entre otras corrientes modernas de la cultura occidental que vuelve a mirar también de nueva manera a otras tradiciones clásicas y contemporáneas.

Con los autores antes mencionados, a los que pronto se sumarán más nombres significativos a lo largo y ancho de todo el continente americano, ${ }^{2}$ se produce la restauración de la prosodia clásica y la renovación

1. La vocación universal y cosmopolita, el gusto refinado y el lujo, la evocación de mundos antiguos y lejanos, son algunos de los elementos juzgados como exógenos por la crítica social que ve en el modernismo una estética de la evasión. Sin embargo, la mirada ecléctica del poeta modernista reconoció y trató otros temas ligados a la identidad cultural de América y dio respuesta a coyunturas históricas y políticas particulares, siendo ejemplo de ello la evocación de culturas aborígenes, con sus mitologías y héroes, y la asunción del rol como poeta civil de la nueva sociedad aún en formación.

2. Deseamos anotar en este punto que a partir del corpus de autores y obras, se puede hablar de al menos tres generaciones de poetas modernistas. La primera es la que integran los autores arriba mencionados; la segunda -donde se afirma la tradición y también ocurre la ruptura dentro del modernismo, tendencia crítica llamada antimodernismo-, la 
del sistema poético de la América hispánica. Ambos aspectos se convierten también en aportaciones latinoamericanas fundamentales a la lengua castellana, cuya influencia -la obra de Darío de más modo notorio- marcará un punto de inflexión de la poesía escrita en esta lengua; asunto acaso no reconocido por la academia española. No obstante, el diálogo cultural del modernismo americano con los autores de la llamada Generación del 98, ${ }^{3}$ por ejemplo, fue relevante, siendo un tópico de interés crítico, sobre el que Juan Ramón Jiménez $(1962,61)$, partícipe y comentarista del fenómeno, diría que se trató de "un movimiento de entusiasmo y de libertad hacia la belleza".

$\mathrm{Al}$ respecto nos preguntamos ahora ¿̨cómo es asumida la conciencia crítica del lenguaje en el modernismo hispanoamericano, al considerar que la confianza plena en la palabra es uno de los principales postulados para superar la crisis humana de finales del siglo XIX, que buscó la salvación estética a través de la trascendencia espiritual? La respuesta la daremos con cuatro comentarios sobre el pensamiento estético de José Martí, José Asunción Silva, Rubén Darío y Medardo Ángel Silva, respectivamente. ${ }^{4}$

integran Ricardo Jaimes Freyre, Amado Nervo, Enrique González Martínez, Guillermo Valencia, Leopoldo Lugones, José María Eguren, Julio Herrera y Reissig y Medardo Ángel Silva; y el tercer momento es el que conforman las voces líricas de Juana de Ibarbourou, Delmira Agustín, Alfonsina Storni, Gabriela Mistral y Dulce María Loynaz. Cabe aclarar que a esta época no se la puede definir bajo el esquema de una escuela estética, orientada bajo un maestro guía como fuera visto Rubén Darío, el único sobreviviente generacional de los jóvenes poetas muertos prematuramente, pues la índole acrática de su ideología estética refuta tal afirmación (ver el numeral $\mathrm{C}$ de las "Palabras liminares" del libro Prosas profanas), mas no su personalidad de tonos ególatras que lo hizo proclamarse a sí mismo, en 1890, mentor del movimiento. En el prefacio a Cantos de vida y esperanza dijo sin modestia alguna: "El movimiento de libertad que me tocó iniciar en América se propagó hasta España" (Darío 1977, 55).

3. De la numerosa bibliografía crítica, y en relación con el significado del movimiento en la historia literaria, cabe destacar el ensayo Celebración del modernismo (1976) de Saúl Yurkievich, el capítulo de análisis estético en Los hijos del limo (1974) de Octavio Paz y el mapa sociocultural que elabora Max Enríquez Ureña bajo la denominación de Breve historia del modernismo (1962). Los estudios editados por Guillermo Díaz Plaja (1951) y Guillermo Carnero (1987) sitúan el inicio y desarrollo del debate sobre la recepción del modernismo en España.

4. Del corpus antológico de obras poéticas que documenta esta reflexión hemos seleccionado solo algunos casos particulares para hacer del análisis crítico un ejercicio de lectura donde sea posible constatar las apreciaciones formuladas con la realidad irremplazable de los poemas. 


\section{JOSÉ MARTÍ: “NADIE TIENE HOY SU FE SEGURA"}

1882 marca la génesis del modernismo como movimiento y como época (Jiménez 1985, 11). La publicación de Ismaelillo de José Martí da inicio a la configuración de los primeros rasgos particulares del lenguaje modernista, como fuera la flexibilización del verso liberado de la retórica romántica y neoclásica. El propio poeta, anota José Olivio Jiménez (1985, 12), poco después, en 1891, escribirá al respecto: "La poesía se corta la melena y cuelga del árbol glorioso el chaleco colorado". Y en el mismo año de 1882, el poeta cubano inicia la redacción de su segundo libro, denominado bajo el escueto pero emblemático título de Versos libres, con el que ejercerá una influencia decisiva en la apertura métrica y rítmica de la nueva lírica de Hispanoamérica, donde la visión existencial y el tono agónico de su poesía, propio de la crisis de fin de siglo, tocará la época con el espíritu crítico y el ideario ético, propuestos como vías de resolución al conflicto de valores que significa la asunción de la vida moderna.

Cabe recordar en este punto que es en la prosa donde se manifiestan los primeros brotes de la renovación idiomática del modernismo. Y es la obra periodística del prócer cubano la que primero exhibe el brillo de las ideas y el lujo de la expresión para hacer de la lengua un ideario ético trascendente. La potencialización artística de la poesía modernista hispanoamericana tiene en el rigor y la belleza verbal de José Martí la lección inaugural, aspecto que será legado a la tradición como fundamento de la identidad de la nueva literatura de América. También en la prosa reflexiva encontramos lo que José Olivio Jiménez $(1985,12)$ llama la primera toma de conciencia del mundo moderno. Nos referimos al prólogo de Martí escrito para el Poema del Niágara del venezolano Juan Antonio Pérez Bonalde. ${ }^{5}$

La nutrida mirada crítica sobre la poesía hispanoamericana exhibida por Martí en ese prólogo, sin duda alguna, se constituye en uno de los balances más lúcidos de una época cultural apenas en formación, mas dotada ya de los valores artísticos que el vacío espiritual de una época necesitada

5. La traducción ejemplar que Pérez Bonalde hizo de El cuervo de Edgar Allan Poe fue el primer paso hacia el encuentro de los modernistas, en particular de José Asunción Silva, con la nueva poesía norteamericana. 
en superar el sentimiento de angustia vivido por la crisis de la transición que, sin embargo, no logra definir el camino futuro de un presente también difuso por la emergencia reciente de los Estados nacionales, ya liberados del dominio europeos pero no a salvo del nuevo coloniaje imperial ni de sus propias decisiones que impidieron transformar la sociedad de entonces. Con respecto a este sentimiento, escribe Martí (1989):

Nadie tiene ya su fe segura. Los mismos que lo creen, se engañan. Los mismos que escriben fe se muerden, acosados de hermosas fieras interiores, los puños con que escriben. No hay pintor que acierte a colorear con la novedad y transparencia de otros tiempos la aureola luminosa de las vírgenes, ni cantor religioso o predicador que ponga unción y voz segura en sus estrofas y anatemas. Todos son soldados del ejército en marcha. A todos besó la misma maga. En todos está hirviendo la sangre nueva. Aunque se despedacen las entrañas, en su rincón más callado, están, airadas y hambrientas, la Intranquilidad, la Inseguridad, la Vaga Esperanza, la Visión Secreta. !Un inmenso hombre pálido, de rostro enjuto, ojos llorosos y boca seca, vestido de negro, anda con pasos graves, sin reposar ni dormir, por toda la tierra, $-y$ se ha sentado en todos los hogares, $y$ ha puesto su mano trémula en todas las cabeceras!- ¡Qué golpeo en el cerebro! ¡Qué susto en el pecho! ¡Qué demandar lo que no viene! ¡Qué no saber lo que se desea! ¡Qué sentir a la par deleite y náusea en el espíritu, náusea del día que muere, deleite del alba!

La condición moderna como crisis espiritual hará del lenguaje un valor plástico de intensa expresividad creadora. No resultará contradictorio entonces que la tensión del tema la resuelva Martí bajo una modalidad musical rítmica, cuyas pausas no le restan dramatismo sino que le aportan intensidad, vigor, potencia a la palabra. Estamos ante un ejemplo de perfecto acoplamiento de idea y expresión. Belleza, ritmo y lujo verbal, decíamos antes, son los primeros valores que se incorporan al patrimonio lingüístico del modernismo por la vía de una poesía liberada de la gravedad retórica y dotada de levedad métrica que no impide conservar lo mejor de la tradición. ${ }^{6}$

6. En la presentación que hace el poeta cubano a sus Versos Libres, dirá: "Amo las sonoridades difíciles, el verso escultórico, vibrante como la porcelana, volador como un ave, ardiente y arrollador como una lengua de lava. El verso ha de ser como una espada reluciente, que deja a los espectadores la memoria de un guerrero que va camino al cielo, y al envainarla en el Sol, se rompe en alas" (Martí 1989). 
Es necesario determinar que si bien la visión del lenguaje es desarrollada desde la confianza que da un positivo dominio formal, la escritura llena con sus signos el vacío existencial de la incertidumbre frente a los problemas de la realidad, sin acaso eliminar ese no saber de la vida más que expresando el temor, la amenaza y el peligro del tiempo que constituye la experiencia secular del mundo moderno, pues la falta de fe y el vacilar de la creencia es la interrupción que advierte el poeta para realizar la obra y hacer de la belleza la unidad de armonía total.

"Las hermosas fieras interiores", mencionadas por José Martí, revelan metafóricamente la convulsión estética del individuo en plena crisis espiritual del siglo XIX que acude a la palabra como salvadora de su condición. Asimismo, la negatividad real de la época moderna encuentra en el imaginario literario la solución posible del mal que aqueja al poeta, quien ha logrado la autonomía expresiva de su mundo interior al crear otro paralelo que restaura de modo utópico los defectos de la realidad. Valga recordar que para el modernista la poesía es belleza redentora de la vulgaridad del mundo y del mal humano preso de las pasiones que lo condenan a la materialidad de los sentidos y el deterioro progresivo e inevitable del tiempo.

No obstante, debemos precisar que la crítica del lenguaje en Martí opera de un modo indirecto a la modalidad lingüística de la cual no se duda. Se trata de oponer los valores morales del lenguaje a la realidad -fidelidad y honradez- para salvar con la belleza verbal el universo individual y proyectarlo al exterior como un estado personal ideal. ${ }^{7}$ La utopía ética del autor cubano le hará postular la trascendencia de la poesía como fidelidad a la vida y régimen de perfección social, de lo cual estará exenta cualquier forma de impostación o falsedad poética, llámese artificio o recomposición, que no sea la experiencia vital interior, profunda. Para sus Versos libres redacta la siguiente confesión:

7. La postura ética del poeta cubano, sin escisión entre vida y obra, debe mirarse como una estética de la sinceridad. La militancia político revolucionaria en busca de la liberación colonial de su país, causa por la que muere en el campo de batalla, asumida tanto en la prosa (discursos, epístolas, crónicas, crítica literaria, novela, literatura infantil, ensayo de tema filosófico y político) y en la poesía, demuestra la sólida convicción que mantuvo del pensamiento como actitud de belleza y libertad. 
Estos son mis versos. Son como son. A nadie los pedí prestados. Mientras no pude encerrar íntegras mis visiones en una forma adecuada a ellas, dejé volar mis visiones: ¡Oh, cuánto áureo amigo que ya nunca ha vuelto! Pero la poesía tiene su honradez, y yo he querido siempre ser honrado. Recortar versos, también sé, pero no quiero. Así como cada hombre trae su fisonomía, cada inspiración trae su lenguaje [...] He querido ser leal, y si pequé, no me avergüenzo de haber pecado. (Martí 1989, 45)

En las estrofas del poema XLVI de Versos sencillos que citamos más adelante, encontramos los tópicos principales de la práctica del discurso metaliterario que postula al poema como motivo de la poesía. Este antecedente martiano de tono confesional y reflexivo de la palabra es importante para situar la concepción moderna del arte autorreferencial en la tradición hispánica, bajo la particular preferencia estética de eludir el artificio en pos de una poesía natural que, sabemos bien, Martí defendió siempre como una manera de mantener la fidelidad por la vida. Recordemos la expresión con la que el poeta buscó ante todo "desembarazar del lenguaje inútil la poesía: hacerla duradera, haciéndola sincera, haciéndola vigorosa, haciéndola sobria; no dejando más hojas que las necesarias" (citado por Jiménez $1985,63)$.

La meditación sobre el sentido negativo de lo artificial nos conduce a recordar que el modernismo llegó a acentuar al límite la distancia entre el lenguaje literario y el habla coloquial. Rafael Lapesa $(1986,444)$ sostiene al respecto que uno de los factores lingüísticos del modernista fue la explícita voluntad de separarse del lenguaje natural y buscar la expresión más lujosa y extraña a lo vernáculo, mediante la erudición mitológica y la dicción de tono libresco. En este sentido, Martí se aleja de tal propósito; sin embargo, debemos considerar que su obra poética es iniciadora de la nueva estética, cuyo modelo servirá para hacer la revisión crítica de la desviación cometida por el exceso de artificialidad verbal en que cayó Rubén Darío.

El discurso metaliterario de Martí parte de afirmar la unidad comunicante del verso. La confianza total y plena del lenguaje constituye la contraparte positiva de la crisis del poeta que experimenta la secularidad del cambio de siglo. La compañía del verso es necesidad vital de diálogo, no decorado o lugar para exhibir vanidad alguna. Si el poema es aposento del ser, voz de los sentimientos, depósito del dolor, es la poesía posibilidad de diálogo con los semejantes y el mundo. El lenguaje adquiere entonces 
una función compensatoria del espíritu. Al ser potencia, el alto valor positivo de la poesía no da cabida a la duda ni a la desconfianza.

Aclaramos que es la autorreferencialidad el valor principal de la poética martiana para allanar el camino de la conciencia crítica. Por ahora permanecemos en el estadio de los poderes vigentes de la palabra para sanar y armonizar al hombre con el universo. Por lo que dirá al inicio del poema: "Vierte, corazón tu pena". Su pasión por la armonía cósmica del lenguaje con los seres y las cosas, se revela en el atributo purificador de la escritura que opera como catarsis de perfección moral. Y en tanto búsqueda de salvación, la estrofa final es ascenso y trascendencia:

¡Verso, nos hablan de un Dios adonde van los difuntos:

verso, o nos condenan juntos, o nos salvamos los dos! (Martí 1989, 49)

\section{JOSÉ ASUNCIÓN SILVA: LENGUAJE E IRONÍA CRÍTICA}

Heredero del pensamiento simbolista asimilado de la poesía onírica de Gustavo Adolfo Bécquer y del misterioso sentido musical y trascendente de Edgar Allan Poe, la vida y obra de José Asunción Silva (1865-1896) estarán marcadas por la tragedia y el espíritu crítico finisecular. Quizás como ningún otro modernista, el poeta colombiano experimenta los desencuentros de la modernidad literaria, que a fuerza estética se abre paso en América. No logró en vida un reconocimiento justo, pues la burla y la incomprensión de sus contemporáneos, sumado al fracaso de sus empresas económicas y proyectos literarios, ${ }^{8}$ signan negativamente su existencia

8. Recordemos algunos sucesos nefastos para la vida del poeta. El primero de los cuales inicia con la muerte temprana del padre, al que sucede sin éxito alguno en la administración de los negocios familiares. La bancarrota económica lo llevará al tribunal por las decenas de demandas de los acreedores. El deceso de su hermana Elvira marcará con pesimismo el espíritu del poeta. A todo esto se suma la pérdida de su obra literaria en el naufragio del barco en que viaja, proveniente de Caracas, como secretario de la Legación de Colombia. Otra frustración es la negativa del gobierno de incorporarlo al cuerpo diplomático en Buenos Aíres, cargo que Rubén Darío había dejado vacante como cónsul de Colombia ante la Argentina. Una interesante reconstrucción biográfica del poeta es la que ofrece Fernando Vallejo en su libro Chapolas negras (1995). 
que terminará con el suicidio ocurrido el mes de mayo de 1896. En Silva, vida y obra se complementan sin explicarse a cabalidad. No obstante, la conciencia literaria frente a la incomodidad producida por el ambiente cultural estrecho de Bogotá, su ciudad natal, se traspondrá, por ejemplo, al conflicto romántico de ignorar el orden secreto del mundo y en la recepción del nuevo arte que ofrece textos como "La respuesta de la tierra" y "Un poema".

En el primero de los títulos arriba anotados, se sostiene un diálogo entre el poeta y la tierra, a la que interroga sobre los grandes misterios existenciales: “¿Qué somos? ¿Adónde vamos? ¿Por qué hasta aquí vinimos?, preguntas trascendentes que evocan "Lo fatal", poema con el que Rubén Darío cierra su libro Cantos de vida y esperanza de 1905. Esta semejanza de visión, propia de la crisis de fin de siglo americano, debemos diferenciarla, pues lo que distingue a Silva del coro modernista es la crítica irónica que Darío, por ejemplo, no desarrolla en su poesía. El silencio final del poema aclarará mejor este asunto, si tenemos en cuenta que con ello se da paso al sentimiento de angustia y de vacío espiritual, sin olvidar acaso que el juego irónico ejercido en la figura desmitificada del poeta, es la apertura a la crítica autorial de la poesía contemporánea hispanoamericana, tópico que retoma Vicente Huidobro de un modo particular bajo la figura del antipoeta, y de la cual Nicanor Parra hará una poética crítica y creativa.

El diálogo en el poema se cierra con la suspensión del lenguaje. Escribe José Asunción Silva:

La tierra, como siempre, displicente y callada, al gran poeta lírico no le contestó nada (Silva 1952, 90)

Sobre el tema del autor, Silva ligará el carácter metaliterario y autorreferencial contenido en "Un poema"; texto con el cual desarrolla un detallado proyecto estético de la nueva poesía, donde "lo grotesco" y "lo trágico" serán motivos vitales del pensamiento artístico. Este fenómeno de extrañamiento de la lírica moderna, que genera la tensión disonante mencionada por Hugo Friedrich $(1974,21)$, es junto a la autorreferencialidad de la poesía, los dos temas sobre los cuales gravita la conciencia crítica de Silva. 
Ecos de los motivos decadentistas (esa "mujer hermosa, idolatrada y muerta"), la sugestión simbolista de tonos vagos y misteriosos, más la presencia de los valores plásticos del prerrafaelismo inglés, ${ }^{9}$ en la música de los alejandrinos pareados, cuyo ritmo cadencioso otorga flexibilidad narrativa al verso, generan la contradicción esencial del poema proyectado, pues la descripción del deseo poético encarna con plenitud en la escritura, no así la recepción negativa del público, que no alcanza a distinguir los valores de la estética propuesta.

La oposición de la figura del poeta, desmitificada por la incomprensión y el fracaso artístico, frente a la singular aparición del juicio que desconoce la naturaleza y el sentido del nuevo arte, viene a ser la prolongación crítica del lenguaje, cuya apertura la situamos en la poética metaliteraria y autorreferencial de José Martí. Leamos los extremos - principio y final- del poema comentado. Las estrofas de Silva $(1952,73)$ dicen:

Soñaba en ese entonces en forjar un poema,

De arte nervioso y nuevo, obra audaz y suprema,

Escogí entre un asunto grotesco y otro trágico

Llamé a todos los ritmos con un conjuro mágico

Le mostré mi poema a un crítico estupendo...

Y los leyó seis veces y me dijo... ¡No entiendo!

Donde José Asunción Silva agudiza su pensamiento crítico moderno es en una parte algo marginal de su obra lírica denominada Gotas amargas, que la historiografía sitúa como el principal antecedente de la antipoesía de Nicanor Parra (Camacho Guizado 1968). Cabe agregar que El libro de versos-obra preliminar editada solo hasta 1908 en Barcelona, junto a los

9. Una definición de esta corriente pictórica y literaria de la segunda mitad del siglo XIX es la siguiente: "Para Taine, lo que ansían representar por el dibujo, el color y la palabra escrita son 'las impresiones de la persona moral, el diálogo silencioso del alma y de la naturaleza, la sorda resonancia de un yo profundo lleno de cuerdas vibrantes de una gran harpa íntima que responde a todos los contactos externos. Para ellos ese yo poderoso es el personaje principal del mundo' ". Según A. Chevrillón, para los prearrafaelistas "lo esencial es el halo de ensueño, de sentimiento, de ideas, de imaginación, el misterioso cortejo espiritual en torno al hecho de conciencia primitiva; porque esencial e independientemente del hombre que contempla, corresponde al objeto, y está ligado a su apariencia como el significado de una palabra a la forma de las letras que lo componen. Este significado y no esta forma, constituye el ser, la realidad". ‘http://www.fortunecity. com/victorian/bronte/785/-prerrafaelismo.html. . 
demás textos líricos y con prólogo de Miguel de Unamuno- contiene el primer cuestionamiento del modernismo dentro del modernismo. ${ }^{10}$ Pero es dentro del conjunto de poemas de "Gotas amargas", donde la conciencia irónica sobre la realidad del mundo y del arte se vuelve conciencia artística plenamente moderna. Allí la poesía participa con la parodia y el sarcasmo, no exento de sentido moral edificante propio del humor, con el cual busca el poeta la ordenación de las cosas.

La sátira es el recurso más empleado para este fin. Veamos un ejemplo de todo lo anotado hasta el momento. En el siguiente fragmento del poema "Filosofías" se realiza un doble cuestionamiento del estatuto literario, orientado al creador y a la obra. Sobre la dualidad del arte y la escritura se acentúa la fuerza que afirma el sentido de la creación moderna basada en el trabajo, en el esfuerzo del artista para crear su obra, esto en términos de inversión intelectual, física y moral. La contraparte de la afirmación es el énfasis oscuro puesto en el carácter vano de tal empeño, pues es el tiempo el juez supremo que juzga con rigor lo que perdura de lo que desaparece. El escepticismo será el talante más notorio del pensamiento poético de Silva, por lo que dice:
Al arte sacrifícate: ¡combina,
Pule, esculpe, extrema!
¡Lucha, y en la labor que te asesina,
-lienzo, bronce o poema-
pon tu esencia, tus nervios, tu alma toda!
¡Terrible empresa vana!
pues que tu obra no estará a la moda
de pasado mañana.

10. En este punto debemos recordar su satírica "Sinfonía de color de fresa en leche", poema preliminar a las "Gotas amargas" y dedicada "a los colibríes decadentes". Dicho poema es el inaugural cuestionamiento de la estética dariana, que luego cobrará mayor relieve con la reacción crítica del antimodernismo de los poetas modernistas posteriores a la primera promoción (Lugones, Herrera y Reissig, Ramón López Velarde, Luis Carlos López), quienes evolucionaron hacia otros tópicos como la ironía, el prosaísmo y la dicción coloquial, sin llegar a romper con los esquemas métrico-rítmicos de los maestros, como lo haría la vanguardia poco después. Recordamos la primera estrofa del poema paródico de Silva $(1952,90)$ que dice: "¡Rítmica Reina lírica! Con venusinos/ cantos de sol y rosa, de mirra y laca/ y polícromos cromos de tonos mil,/ oye los constelados versos mirrinos, escúchame esta historia Rubendariaca,/ de la Princesa verde y el paje Abril,/ rubio y sutil". 
En diálogo con lo anterior, la experiencia de la fugacidad y el sentido misterioso de la vida latente en los objetos, hace de "La voz de las cosas" el poema donde el bogotano encara la cuestión del poder del lenguaje para asir la esencia simbólica de la comunicación con el mundo.

De clara resonancia romántica es la idea aquella de detener el tiempo con las palabras y recuperar la belleza del instante. Pero no se trata de una trasposición directa de lo real, sino de aprehender lo esencial para cifrarlo melódicamente con las veladuras y las sombras sonoras del verso. A esto se dirige el empeño del autor, solo que el poema sirve para postular un programa, no para ejecutarlo, por lo que el enunciado, reiterativo, es "Si os encerrara yo en mis estrofas [...] Si aprisionaros pudiera el verso". Sobre la interioridad de la palabra, ese diálogo secreto que aflora en el poema para hacer visible lo desconocido, Silva deposita la fuerza verbal de su deseo de aprehensión estética. Valga recordar que la obsesión del tiempo es la esencia problemática de la modernidad, por lo cual ese trasponer lo perdido al lenguaje resulta el mayor ideal de una empresa humana que hace de la duda o la negación el camino de la certeza y la posibilidad.

\section{RUBÉN DARÍO: LA CREENCIA DE LA POESÍA Y SUS LÍMITES VERBALES}

La confianza en la palabra y el manejo pleno del lenguaje fueron los principales atributos del poeta nicaragüense. Sin duda es el modernista que más usos diferentes dio a la palabra. Logró definir en un único estilo, a través de síntesis y fusión verbal, los múltiples registros de un arte sincrético y ecléctico. La historia literaria hispanoamericana debe a Darío el haber transformado la realidad poética y consolidar con ello una manera propia de afirmación cultural, no exento de críticas sociopolíticas acaso equívocas sobre la presencia en su obra de elementos exógenos de la realidad americana, y dado el carácter evasivo de su estética predominante de la idea platónica de belleza; ${ }^{11}$ lo que al cabo del tiempo no ha impedido reconocer su vigencia y magisterio poéticos (Rama 1977).

11. Dado "el gusto por la aristocracia del pensamiento y por la nobleza del Arte" como el propio autor lo afirmara (Darío 1977, 155). 
Tanto el genio y el temperamento creador para dotar de sonido y formas nuevas al sistema verbal castellano que critica de anquilosado, casi “a punto de [la] momificación del ritmo" (Darío 1977, 155), lo convierten en el artífice de la palabra. Darío es "el gran poeta exquisito", que sin llegar a ser el poeta de América, como lo señaló con justa razón José Enrique Rodó (1957) en su temprano estudio de Azuly Prosas profanas, ${ }^{12}$ logra incorporar en la poesía la realidad múltiple de una lengua que se alza de su suelo colonial, para formar parte de la mejor tradición moderna de la literatura de Occidente.

La confianza radical en la palabra lo lleva a ostentar el lujo y la perfección de una obra, que por la vía del ingenio también lo condujo a tocar el límite permitido de la expresión comunicativa. Justo allí donde las conquistas y hallazgos fundamentales se convierten en degradación y decadencia verbal de una poesía revestida de artificio exquisito y hastiada de cultura libresca. Baste recordar al respecto del exceso de utilizar siempre un lenguaje poético, las críticas de Luis Cernuda (1971, 267-78) en su ensayo "Experimento en Rubén Darío". Fascinado por la perfección de una expresión pura, su limitación más nociva consistió en no transgredir esa certeza y romper con el círculo de la autoimitación, según sostiene Guillermo Sucre $(1985,40)$, pues afirma que "no era raro que ello le ocurriera a un poeta como él: sus dones eran tan extraordinarios que podía confundir, en un momento dado, la facilidad y aun la riqueza con la verdadera creación".

Los materiales prestigiosos, las palabras brillantes y sonoras fueron su debilidad para hacer de una poética el culto al lujo y a la perfección de la palabra. Otro camino apenas señalado por el maestro a sus contemporáneos -el de la crisis del lenguaje-, es el que guiará a los demás poetas (Lugones y Herrera y Reissig, López Velarde y Luis C. López) hacia la profundización de sus mejores logros. La reacción fecunda del modernismo llevada a cabo al seno mismo de su estética, recordemos, no fue tanto la negación de Rubén Darío como su apertura hacia los tópicos que no fueron desarrollados por él, en cuya proyección prevalecerá la desproporción y la asimetría características de la conciencia literaria moderna.

12. Al respecto véase el capítulo "La sensibilidad americana" del libro La máscara, la trasparencia. Ensayos sobre poesía hispanoamericana de Guillermo Sucre (1985, 19-26). 
De su legado tomamos la noción del poema como un organismo verbal capaz de encarnar la representación perfecta de sentido y sonido. La visión armoniosa del mundo que lo sustenta es del tipo romántico, pues Darío funda su poética en la concepción de la analogía, donde nada se opone en el universo porque todo en él se corresponde: lo material es un correlato de las fuerzas espirituales, como es lo visible de lo invisible, lo audible de lo inaudible, así todo dentro del microcosmos de la palabra que contiene en su cifrar simbólico el sentido de lo vivo, incluso del universo todo. Por lo que dirá en las "Palabras liminares" de Prosas profanas de 1896: "Cada palabra tiene un alma, hay en cada verso, además de la harmonía verbal, una melodía ideal” (Darío 1977, 70).

Recordemos además que para Darío la única religión es el arte, cuya supremacía con respecto de la vida la ejercen a cada momento las potencias creadoras del lenguaje. Las fuerzas negativas, la violencia de la muerte, por ejemplo, que disocian y generan crisis, las atenúa hasta casi desaparecer, mediante el uso de la palabra, justa y exacta de la melodía purificadora. Esa palabra poética sobre la que no cae mancha alguna de sospecha o recelo -herencia de la visión romántica del lenguaje como doble del universo, como argumenta Octavio Paz (1974) - le hará explorar las posibilidades comunicantes de la poesía para asir el mundo, para conocerlo y transformarlo en ritmo y así gozar de su belleza.

La brecha entre realidad y representación lingüística pareciera estar cerrada por la vía técnica, pues el poema, al ser un objeto de arte y una manufactura, revela su condición subordinada al hombre como artificio verbal que reemplaza tanto lo vulgar como la mediocridad humana, y le restituye a esa realidad desmejorada y pobre la nobleza social y la dignidad estética perdida que requiere el poeta para vivir. Mas la dominación del lenguaje será también el camino de la ley de contrarios que rige el sistema poético de Darío, pues el silencio aparece en su obra para fundar el estado negativo de la creación moderna, donde el poema de carácter autorreferencial y naturaleza metaliteraria sirve a la formulación del programa artístico de un ideal que se torna fracaso. Si el deseo de absoluto es lo que concentra al poeta en su obra y le hace desear lo imposible, la vocación de trascendencia y la tentación del límite le harán tocar el extremo final del lenguaje. Silencio, mudez e impotencia ocupan el espacio de la escritura. 
Dentro del ámbito temático del modernismo como movimiento ecléctico y sincrético de restauración y renovación lírica de la lengua española, la reflexión metapoética no es escasa en Darío, aunque tampoco sea muy prolifera. Lo importante será el hecho de formular un sentido crítico de la autoría y del ser de la escritura. Recordemos antes que la manera con la cual se realizó la meditación del hecho literario fue a través de la utilización de símbolos y no bajo la modalidad de la alusión expresa al problema de la representación como lo hará luego el poeta vanguardista. En la figura del cisne ${ }^{13}$ recae principalmente el sentido verbal del modernismo para cifrar el ideal artístico y concentrar el poder de la belleza, dados los valores de elegancia, plasticidad, misterio y pureza legados de la tradición europea.

$\mathrm{Al}$ interpretar la construcción de esta imagen poética, encontramos abierto el camino hacia la meditación del hecho literario mismo. Rubén Darío (1977, 80) cierra la segunda edición de Prosas profanas de 1901 con el soneto titulado "Yo persigo una forma...", emblemático ejercicio de concisión verbal para referirse al silencio, en el cual aparece el "ave de la luna sobre el lago tranquilo", como alusión cifrada de la poesía, que reaparece al final del poema en la forma enigmática de una pregunta devuelta al autor sin respuesta. El soneto todo es una gran interrogación trascendente sobre la poesía. El movimiento dual que afirma la búsqueda parte de reconocer una carencia:

Yo persigo una forma que no encuentra mi estilo, botón de pensamiento que busca ser la rosa; se anuncia con un beso que en mis labios se posa al abrazo imposible de la Venus de Milo (Darío 1967, 622).

La escritura, en tanto estilo del autor, identidad y única presencia, encarna el conflicto de la representación suspendida de la música. El ritmo interrumpido, en el paso del deseo al de la forma, ha dejado de fluir y el

13. El soneto de Enrique González Martínez titulado "Tuércele el cuello al cisne ..." con el cual se declara el necesario cambio de sensibilidad estética, pues para entonces (1911) la impronta parnasiana de Darío se había desgastado. El poeta mexicano propone el reemplazo de "el cisne de engañoso plumaje" por "el sapiente búho" americano. Esta actitud crítica se ha visto como la voluntad de alcanzar un punto diferente de evolución interior del modernismo, que permita superar la afectación retórica y los virtuosismos meramente decorativos (Jiménez 1985, 275-80). 
silencio abre su sombra en mitad del pensamiento para intensificar más la vocación de absoluto cargada de una fuerte atmósfera de sacralidad pagana. El ideal poético de la belleza es primero pensamiento, surge de la imaginación antes de reposar en la forma esquiva del lenguaje que lo cifra en un símbolo natural como la rosa, y que encuentra su correspondencia artística en la escultura -tópico caro de la poética dariana- para proyectar la unidad del universo artístico en la totalidad de la obra.

Mas la impotencia se instala en la conciencia del poeta para marcar la distancia que separa la realidad de su deseo. El balbuceo de la voz se escucha cuando la visión del poeta se sabe apartado de la luz cercana que ilumina lo imposible del decir. Es lo inconcluso, lo inacabado del habla poética (el reflejo de la luna, la iniciación melódica de la flauta, las barcas del sueño, el sollozo de la fuente) donde el silencio actúa para que el poema sea otra forma de lo imposible. No puede ser más contundente el resultado de tal empeño:

Y no hallo sino la palabra que huye.

\section{MEDARDO ÁNGEL SILVA: LA PASIÓN INEFABLE}

La crisis finisecular en Medardo Ángel Silva encarna de modo ejemplar como mal de vivir. "Mi dolor de vivir es un dolor de amar", sentencia pronto este muchacho nacido en Guayaquil en 1898 y muerto por su propia mano a los 21 años, en 1919, tras una crisis sentimental que lo llevó a tomar esa trágica decisión. Por lo controvertible del hecho, sin embargo, que también signara a otros poetas de su generación, y marcara el destino literario de Ecuador en la modernidad, ${ }^{14}$ el significado en juego de tal ges-

14. Al respecto sostiene Cristóbal Garcés Larrea $(1950,1)$ : "la generación de Medardo Ángel Silva irrumpe al comienzo del siglo y la integran a más de Silva los más finos y dolorosos poetas que haya tenido Ecuador: Arturo Borja, Ernesto Noboa Caamaño, Humberto Fierro y José María Egas". En lo concerniente al carácter de este grupo, llamado por Raúl Andrade "la generación decapitada", se destaca el hecho de compartir el aciago sino de los "fin de Raza", pues, precisa el crítico, "eran trágicos, enfermos de melancolía e inadaptados al rudo medio ecuatoriano y realizaron una honda poesía enlutada, de insatisfacción, de temor a la vida y de ansias de evasión" (Garcés Larrea 1950, 1). Una lectura actual que pondera juicios como el anterior, valora otros tantos como aporta nue- 
to es preciso de incorporar a su obra como el último acto de comunicación trascendente, para acaso comprender cómo su literatura no constituye una exterioridad de la existencia ni crea una escisión entre vida y obra. Dicotomía que fuera un principio estético seguido por Rubén Darío, José Asunción Silva o Guillermo Valencia, bajo los influjos del parnasianismo francés que estableció la jerarquía del arte por el arte en detrimento de la vida cotidiana, al ser considerada su realidad algo pobre y vulgar.

Hacemos referencia a esa circunstancia personal del poeta ecuatoriano no solo a modo de prueba de un carácter sensible y frágil sino mejor como una actitud esforzada ante la vida que lo hace sentir la angustia de la expresión poética de una manera extrema, honda y profunda, vinculado a su ser mismo, si bien el propio vocablo latino angustia lo designa en su acepción inicial de nombrar la opresión física, la dificultad misma de respirar y, por tanto, de comunicar, de existir. Esto en cuanto la crisis poética en él no responde a una preocupación exógena por el lenguaje y la escritura, ni menos es algo tratado tan solo bajo la forma novedosa de un motivo literario más de los muchos que la constelación modernista frecuentó con algo de puerilidad exquisita en su repertorio sorprendente cuando restauró antiguos tópicos y compuso nuevos temas.

Por el contrario, la angustia y el dolor como elementos constitutivos del sentido de la vida, en este poeta, lo son también de su obra literaria. Creemos que este aspecto funda uno de los cimientos de su poética, en particular de aquella obra en verso no incluida en su libro de 1918 titulado El árbol del bien y del mal, que llevara a la crítica de su momento a ver en este autor a otro amante del lujo que buscó hacer de la literatura, paralela de su vida modestísima, una existencia artificiosa (Caillet Bois 1967, 1153).

Y más que mero modernista -y lo es por los recursos literarios que domina y toda la apetencia formal de la prosodia que su precocidad supo transformar en estilo propio-, Medardo Ángel Silva es un romántico, hijo del espíritu finisecular encarnado en ideales de vida en crisis y no de los programas estéticos de la escuela europea trasplantados a nuestra América.

vas valoraciones, con inteligencia y tino críticos, es la disertación doctoral de Fernando Balseca Franco (2009) dedicada a reflexionar la modernidad literaria en Ecuador, desde diferentes ámbitos (social, cultural y literario), donde la obra en prosa y verso del poeta de Guayaquil es el eje del cual gravita el horizonte de mayor análisis. 
Entre las corrientes artísticas y las ideas literarias que nutren el eclecticismo modernista, recordamos, quizás sea el espíritu del amor carnal y cósmico, como libertad humana, la fuerza de mayor potencia creadora. Y esa elección le lleva a decir: "Se va con algo mío la tarde que se aleja” (Silva 1965, 1155). Lo declarado por el poeta de Guayaquil no es tan solo la soledad del sentimiento, el desasosiego melancólico, ni la desposesión contemplativa del mundo que disminuye el sentido vital de la existencia, dados por el eco tenue de la queja, de la pesadumbre que habita por igual el cuerpo y los afectos, sino quizás la rotunda declaración de pertenecer a la naturaleza, de formar parte de un orden supremo lo que hace intenso el deseo de integrarse a los elementos para trascender la condición mortal.

Y esa comunión estética con lo telúrico, donde la mujer actúa como médium del universo natural, es lo que instala la poética de Medardo Ángel Silva en el torrente modernista al modo de una erótica y hace de su pensamiento romántico una actitud libertaria moderna, consciente de que el límite al deseo y sus lamentos lo establece la muerte del cuerpo grávido que anhela "ser canoro, ser suave -trino, perfume, canto, crepúsculo o aurora-" (Silva 1965, 1155); esencia por la cual esa pasión de vivir la vida silvestre, de ser vida a cada instante locuaz, lo sitúa en el tiempo largo de la indigencia comunicativa, y lo convierte, como su poema mismo que a continuación glosaremos, en un "mendigo".

$\mathrm{Al}$ respecto de esta idea veamos con algún detalle, en la primera estrofa, esa aparente paradoja del verbo encarnado que no logra decir con palabras lo que el sentimiento contiene. Asunto que para nada puede ser considerado un problema intelectual ni menos un conflicto de la razón, por cuanto la tensión se asienta en el espíritu de lo sensible, en la aeithesis:

¡Oh, angustia de querer expresar lo inefable,
cuando, ave prisionera, una emoción agita
sus alas en la cárcel del verbo miserable
que no traduce en ritmos su dulzura infinita! (Silva 1965, 1154)

Qué es lo inefable en el verso que angustia al poeta hasta el límite de ver reducido su estado, sino la impotencia humana ante lo inconmensurable de la vida, su hondo misterio, por nosotros tratado en esta reflexión como un asunto ontológico, donde el lenguaje es la evidencia de una crisis, cuya crítica interna a la palabra lo es también del mundo social. Allí 
donde la comunicación humana con el universo se vuelve pugna y conflicto, y la única certidumbre que resta consiste en declarar la inconformidad o representar la batalla entre el ser y la palabra, mediante la duda, la queja o el recelo manifiesto ante los poderes perdidos del lenguaje y la facultad debilitada del habla y la escritura, es cuando se instaura la conciencia crítica del artista moderno.

De modo reiterado Medardo Ángel Silva hace suyo el mal de vivir como condición que es soportable solo cuando piensa y siente el amor humano bajo el ideal de unidad con el universo, sea cuerpo o naturaleza. Por ello su tentativa expresa es hallar el ritmo perfecto, la consonancia con el mundo, preso en la forma que no encuentra plenitud ni tampoco garantía alguna de lograr por su efecto desalojar ese sentimiento opresivo y oprobioso de tener la palabra y no la esencia de las cosas.

Pese a la carga espiritual en la cual el dolor humano se convierte, el placer es una búsqueda incesante del poema que fundamenta el sentido de la vida en la escritura, en el canto. El joven poeta insta por la posibilidad de establecer el diálogo con el universo, siendo ese universo interior un acorde del verbo musical vinculado al orden transcendente de la naturaleza. Sin duda que esta idea tiene mucho que ver con el sentido pitagórico de Darío $(1967,617)$ cuando dijo: "Ama tu ritmo y ritma tus acciones".

La crítica del lenguaje, como crisis de la expresión humana, es la disonancia musical del ser con el mundo. Tal vez por ello los símbolos de la poesía referidos por Medardo Ángel Silva en las criaturas aladas que surcan su mirada y pulsan el latir de su corazón enamorado sean las aves, los pájaros. Estas presencias permiten al tiempo de orientar el sentido transcendente del mito icárico del hombre expulsado de las alturas que se precipitan sin remedio a la tierra, construir los términos de comparación con nosotros, al decir de Heidegger, los seres terrestres que tenemos el poder de morir.

La segunda estrofa desarrolla este conflicto que se instaura no tanto en la diferencia de naturalezas - una aérea y, por ende, superior; otra terrenal, pedestre, y por ello mismo, inferior e imperfecta-, como en la semejanza de facultades para el canto:

¡Ay, vale más el pájaro, cuya garganta trina su amor y su dolor, que la lengua del hombre, cuya alma dolorosa lo infinito adivina, siente la eternidad ..., y no sabe su nombre! (Silva 1965, 1155) 
La evidencia del canto constituye al tiempo su carácter misterioso, de ser realidad secreta, materia vedada al conocimiento humano. Lo paradojal de la crisis de la palabra y la consecuente crítica del lenguaje en Silva consiste en que la escritura poética encuentra pero no conoce lo hallado, que solo expresa un sentir, un pensar pero no retiene el sentimiento ni puede aprehender las ideas. Acaso se trate de una mirada sagrada de la poesía como el último ámbito de lo divino que supervive en la modernidad secular donde parece terminar toda forma de vida trascendente.

Y es de nuevo la voz tutelar de Darío la luz que nos llega para recordar que este sentimiento sombrío, que empaña la revelación en la cual el joven trágico ausculta sin renuncias, es llamada "lo fatal", siendo de nuestra naturaleza, todo porque nada conocemos y todo sospechamos, pues ese "no saber adónde vamos/ ni de dónde venimos" (Darío 1967, 688), es el espíritu de la época que orientará el devenir crítico y creativo de la poesía en Hispanoamérica, con la cual el poeta de Nicaragua cierra nuestra reflexión. *

\section{Bibliografía}

Balseca Franco, Fernando. 2009. Llenaba todo de poesía. Medardo Ángel Silva y la modernidad. Quito: Universidad Andina Simón Bolívar, Sede Ecuador / Taurus.

Caillet Bois, Julio. 1965. "Medardo Ángel Silva". En Antología de la poesía hispanoamericana, 1153-6. Madrid: Aguilar.

Camacho Guizado, Eduardo. 1968. La poesía de José Asunción Silva. Bogotá: Universidad de los Andes.

Carnero, Guillermo. 1987. El modernismo español e hispanoamericano. Córdoba: Diputación Provincial.

Cernuda, Luis. 1971. Poesía y Literatura. Barcelona: Seix Barral, Barcelona.

Chevrillón, A. Consulta en hhttp://www.fortunecity.com/victorian/bronte-/78 $5 /$ prerrafaelismo.html.

Darío, Rubén. 1954. Poesías completas. Madrid: Aguilar.

—. 1977. Poesía. Caracas: Biblioteca Ayacucho.

Díaz Plaja, Guillermo. 1951. Modernismo frente Noventa y ocho. Madrid: Espasa-Calpe.

Friedrich, Hugo. 1974. La estructura de la lírica moderna. Barcelona: Seix Barral. Garcés Larrea, Cristóbal. 1950. "Tres poetas ecuatorianos". En Medardo Ángel Silva, Jorge Carrera Andrade y César Dávila Andrade. Sus mejores versos. Cua- 
KİPUS 45, enero-junio 2019

dernillo de poesía dirigidos por Simón Latino n. ${ }^{\circ}$ 24. Bogotá: La Gran Colombia.

Gutiérrez Girardot, Rafael. 1983. Modernismo. Barcelona: Montesinos.

Henríquez Ureña, Max. 1962. Breve historia del modernismo. México: Fondo de Cultura Económica.

Jiménez, José Olivio. 1985. Antología crítica de la poesía modernista hispanoamericana. Madrid: Hiperión.

Jiménez, Juan Ramón. 1962. El modernismo. Notas de un curso (1953). Madrid: Aguilar.

Martí, José. 1989. Obra Literaria. Caracas: Biblioteca Ayacucho.

Paz, Octavio. 1956. El arco y la lira. México: Fondo de Cultura Económica.

- 1974. Los hijos del limo. Barcelona: Seix Barral.

- 1986. Los signos en rotación y otros ensayos. Madrid: Alianza Editorial.

Pérez Parejo, Ramón. 2002. Metapoesía y crítica del lenguaje (De la generación de los 50 a los novisimos). Cáceres: Universidad de Extremadura.

Rama, Ángel. 1984 [1977]. "Prólogo”. En Poesía de Rubén Darío. Caracas: Biblioteca Ayacucho.

Rodó, José Enrique. 1957. “Rubén Darío”. En Obras completas, 163-87. Madrid: Aguilar.

Rocha Barco, Teresa. 1998. "Viena fin de siglo: sombras y horizontes". En Miscelánea vienesa, editado por Teresa Rocha Barco, 11-28. Cáceres: Servicio de Publicaciones Universidad de Extremadura.

Silva, José Asunción. 1952. Poesías completas seguidas de prosas selectas. Madrid: Aguilar.

Sucre, Guillermo. 1985. La máscara, la trasparencia. Ensayos sobre poesía hispanoamericana. México: Fondo de Cultura Económica.

Vallejo, Fernando. 1995. Chapolas negras. Una biografía de José Asunción Silva. Bogotá: Alfaguara.

Yurkiévich, Saúl. 1976. Celebración del modernismo. Barcelona: Tusquets. 